\title{
CFD Analysis of a Triple Concentric Tube Heat Exchanger having water flowing at three different temperatures
}

\author{
Dilpak Saurabh P..$^{*}$, Harshal Khond ${ }^{\dagger}$ and Mandar M. Lele ${ }^{\dagger}$ \\ †Mechanical Engg. Department, MAEER's MIT College of Engineering, Savitribai Phule Pune University, Pune, India
}

Accepted 02 March 2016, Available online 15 March 2016, Special Issue-4 (March 2016)

\begin{abstract}
The present study would include heat transfer CFD analysis for a concentric triple tube heat exchanger. Theoretical studies are carried out for numerical simulations and evaluation of heat transfer. The performance of Triple Concentric Tube Heat Exchanger is to be evaluated at variable operating conditions. Studies and experimentation have already been carried out for $\mathrm{N}-\mathrm{H}-\mathrm{C}$ and $\mathrm{C}$-H-Nconfiguration in Triple Tube Heat Exchanger. The numerical investigation also has already been carried out for various operating conditions. CFD analysis is used to validate the experimental data specifically for $\mathrm{N}-\mathrm{H}$-C configuration in the present study.
\end{abstract}

Keywords: Triple Concentric Tube Heat Exchanger, CFD Analysis, N-H-C Configuration.

\section{Introduction}

The need to understand the transfer of heat between various systems pertaining to the industrial as well as residential applications is an important process which has motivated the research community to improve in the design and performance of heat exchanger devices in recent years. The various applications such as space heating, air conditioning, power production, waste heat recovery, and chemical processing are important fields of study involving heat exchangers. The useful applications of heat exchanger in food industry also cannot be undermined as the various applications such as pasteurization, sterilization, drying, evaporation, cooling, or freezing applications are mainly related to the heat exchanger. Based on the type of flow, type of construction and mode of contact between the fluids, heat exchangers are classified as parallel-flow, counterflow, and cross-flow; tubular or Triple Concentric Tube Heat Exchangers; and direct or indirect types of heat exchanger respectively. The type of heat exchanger to be used is determined by the process and the product specifications. The performance of the heat exchanger generally depends on the various physical characteristics of the fluid and the material. In order to achieve the maximum efficiency of heat exchanger, many researchers have put their effort to maximize the performance along with reduced cost and size.

Triple concentric-tube heat exchangers are used for different products and are found in dairy, food, beverage and pharmaceutical industries. Almost all liquid products can be pasteurized through one of

${ }^{*}$ Corresponding author: Dilpak Saurabh P. these heat exchangers. Examples of such products are milk, cream, pulpy orange juice, apple mash, liquid eggs, sauces, etc. Triple concentric-tube heat exchangers improve the heat transfer through an additional flow passage and a larger heat transfer area per unit exchanger length compared to a double concentric-tube heat exchanger.

In order to optimise the effectiveness of the heat exchangers, and consequently the energy consumption and cost, more accurate and general methods of prediction of their thermal and fluid-dynamic behavior are required. The inherent complexity of the heat exchanger design in aspects such as geometries and fluid flow patterns, means that the possibilities of analytical solutions are very limited without assuming stringent simplifications

Significant researches and development in the field of heat exchangers have led to conclude that the efficiency of a triple tube heat exchanger is higher to that of a double pipe heat exchanger which is used in dairy, food, beverage and pharmaceutical industries Quadir et al.

G.A. Quadir et al carried out the investigation for the performance of a triple concentric pipe heat exchanger numerically using finite element method (FEM) under steady state conditions for different flow arrangements and for insulated as well as noninsulated conditions of the heat exchanger. The three fluids being considered were hot water, cold water and the normal tap water. The results are presented in the form of the dimensionless temperature variations of the three fluids along the length of the heat exchanger for their different flow rates. It is found that the numerical predictions of the temperature variations of 
the three fluids by using FEM follow closely to those obtained from experiments both in magnitude and trend provided correct overall heat transfer coefficients are used. Parametric studies are also carried out to show the effect of the individual design parameter on the performance of the heat exchanger.

They studied experimentally the performance of a triple concentric pipe heat exchanger under steady state conditions for two different flow arrangements, called $\mathrm{N}-\mathrm{H}-\mathrm{C}$ and $\mathrm{C}-\mathrm{H}-\mathrm{N}$, and for insulated as well as non-insulated conditions of the heat exchanger. The three fluids being considered were hot water, cold water and the normal tap water. Under $\mathrm{N}-\mathrm{H}-\mathrm{C}$ arrangement, normal water flows in the innermost pipe, hot water flows in the inner annulus, and the cold water flows in the outer annulus. All fluids flow parallel to each other. Cold and normal water are interchanged in the $\mathrm{C}-\mathrm{H}-\mathrm{N}$ arrangement keeping hot water flow unchanged. The results are presented in the form of the temperature variations of the three fluids along the length of the heat exchanger for their different flow rates. It is found that the temperature variation along the length of pipe differs substantially for the two arrangements. Temperature of cold water increases rapidly in the non-insulated condition of $\mathrm{N}-\mathrm{H}-\mathrm{C}$ arrangement. Cross over points are found in $\mathrm{N}-\mathrm{H}-\mathrm{C}$ arrangement for higher volume flow rates of the three fluids

\section{Experimentation Details}

The experimentation on the TCTHE was carried out by G. A. Quadir et al. In order to predict the thermal performance of the three concentric pipe heat exchanger, the exit temperatures of all the fluids flowing through the heat exchanger are to be known. For this, the finite element method is used. In order to verify the numerical results, a set of experiments were conducted by fabricating the triple pipe heat exchanger subjected to three fluids i.e. hot water, cold water and normal tap water flowing in three pipes of the heat exchanger. In order to carry out experiments, a triple concentric pipe heat exchanger was fabricated. The three pipes used in the fabrication of the heat exchanger are made of stainless steel 40S-Schedule, ANSI/ASME 36.19. Outside diameters of the three pipes are $0.0508 \mathrm{~m}, 0.0762 \mathrm{~m}$ and $0.1016 \mathrm{~m}$ respectively with thickness of each pipe as $1.5 \mathrm{~mm}$ only. The three fluids, namely hot water, cold water, and normal water are pumped from three different tanks to the heat exchanger as shown in Fig. 1. The normal water flows through the inner most pipe, hot water flows though the inner annulus formed between $0.0508 \mathrm{~m}$ pipe and $0.0762 \mathrm{~m}$ pipe and the cold water flows though the outer annulus formed between $0.0762 \mathrm{~m}$ and $0.1016 \mathrm{~m}$ pipe. This arrangement of flow of different fluids is called $\mathrm{N}-\mathrm{H}-\mathrm{C}$ configuration of the heat exchanger as shown in Fig. 1. The flow of fluids can be reversed to represent counter-current flow arrangements.
But here, we are only interested in the analysis of temperature outputs for $\mathrm{N}-\mathrm{H}-\mathrm{C}$ co current flow arrangement.

The water starts flowing from the tank through the pump, passes through the Rotameter measuring the volume flowrate, and enters the heat exchanger inlet. The fluid temperature $\mathrm{s}$ along Type $\mathrm{T}$ thermocouples are used to measure the temperature variation along the length of the heat exchanger are measured using 15units of thermocouple of type T. For each fluid, two thermocouples at entry and exit and three thermocouples placed 1mapart from the entry or exit of the heat exchanger are mounted. In order to take all the readings of temperature at the same time, the thermocouples are connected to Agilent 22Channel Data Acquisition System (DAQ) with a tolerance of $\pm 0.1^{\circ} \mathrm{C}$. All the temperature readings were taken simultaneously only after they were stable as shown by the DAQ.

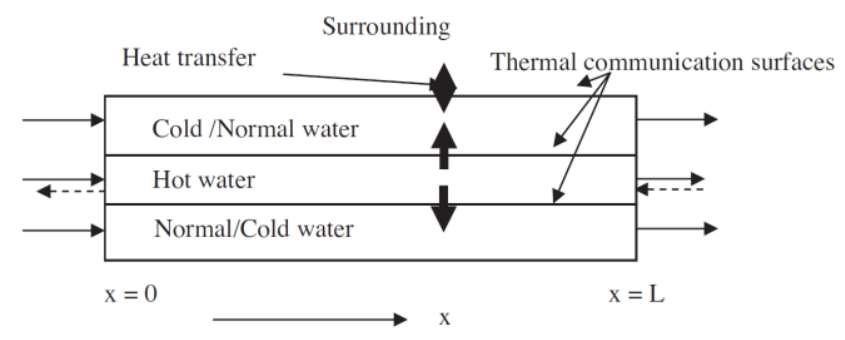

Fig.1 Schematic of the TCTHE

\section{Results of Experimentation}

The first set of experimental results in terms of temperature variations of different fluids along the length of the insulated heat exchanger for co-current flow under $\mathrm{N}-\mathrm{H}$-Carrangement is presented in Fig. 2a when the volume flow rate of the three fluids is the same, i.e. $\mathbf{V}_{\mathbf{n}}=\mathbf{V}_{\mathbf{h}}=\mathbf{V}_{\mathbf{c}}=\mathbf{3 5 1} / \mathrm{min}$.

It is observed from Fig. 2a that the hot water temperature drops to $\mathbf{3 0 . 7 6}^{\mathbf{O}} \mathrm{C}$ from its entry temperature of $52.11^{\circ} \mathrm{C}$; the normal water and the cold water temperatures are increased to $34.89^{\circ}$ Cand $21.98^{\circ} \mathrm{C}$ respectively from their entry temperatures of $28.23{ }^{\circ} \mathrm{C}$ and $10.23{ }^{\circ} \mathrm{C}$ respectively due to the heat exchange between the fluids.

When the volume flow rate of the hot water is reduced to $\mathbf{V}_{\mathbf{h}}=\mathbf{2 0} \mathbf{~} \mathbf{~} / \mathbf{m i n}$ while the volume flow rate for the normal and cold water are kept same as $\mathbf{V}_{\mathbf{c}=\mathbf{V}} \mathbf{V}_{\mathbf{n}}=\mathbf{3 5}$ $\mathbf{l} / \mathbf{m i n}$, a different temperature distribution for three fluids is obtained as shown in Fig. 2b. It is noted from this figure that the hot water temperature drops to $39.44^{\circ} \mathrm{C}$ from its entry temperature of $51.07^{\circ} \mathrm{C}$; the normal water and the cold water temperatures are increased to $31.18{ }^{\circ} \mathrm{C}$ and $18.56^{\circ} \mathrm{C}$ respectively from their entry temperatures of $28.30{ }^{\circ} \mathrm{C}$ and $10.27{ }^{\circ} \mathrm{C}$ respectively. 


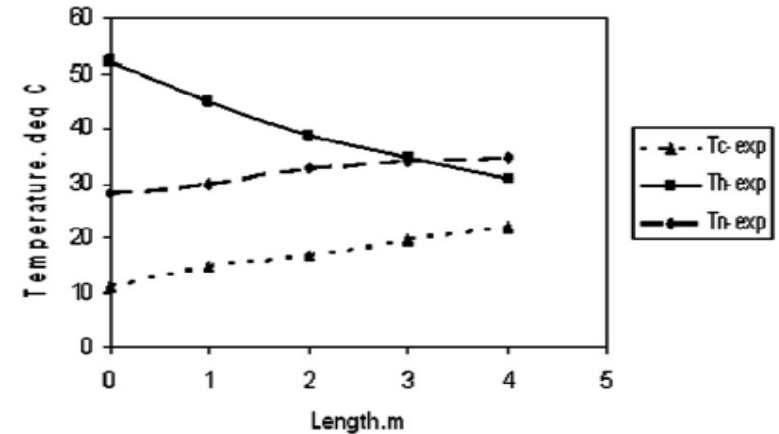

(a)

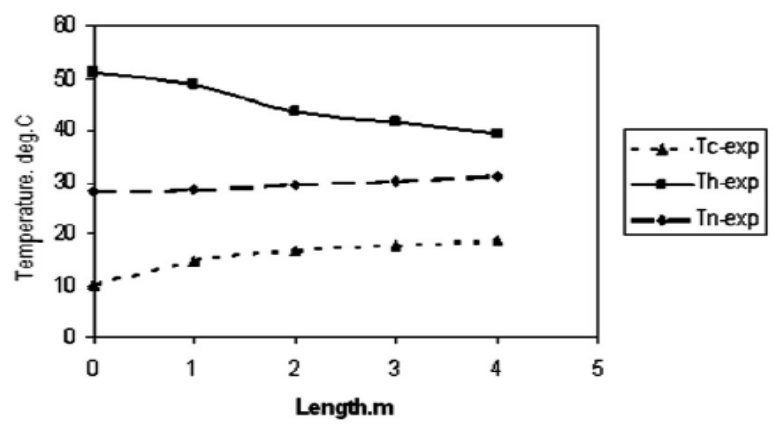

(b)

Fig. 2 Temperature distribution of three fluidsalong the length ofheat exchanger under $\mathrm{N}-\mathrm{H}-\mathrm{C}$ configurationfor co-current and insulated conditions.

(a) $\mathrm{V}_{\mathrm{n}}=\mathrm{V}_{\mathrm{h}}=\mathrm{V}_{\mathrm{c}}=35 \mathrm{l} / \mathrm{min}$ (b) $\mathrm{V}_{\mathrm{h}}=20 \mathrm{l} / \mathrm{min} ; \mathrm{V}_{\mathrm{n}}=\mathrm{V}_{\mathrm{c}}=$ 35l/min Quadir et al.

\section{CFD Analysis}

CFD Analysis was done in ANSYS FLUENT SOLVER using k- $\varepsilon$ Realizable model; we used the Least Square scheme for pressure whereas, upwind schemes were used for other parameters.

After exhaustive work like, modelling, meshing and analysis using solver fluent we came up with the output readings. Some of the contours of temperature distribution in $\mathrm{N}-\mathrm{H}-\mathrm{C}$ arrangement for co courrent flow with similar volume flow rate, i.e. $351 / \mathrm{min}$ is as shown as follows; Fig. 3 shows the contours for various tubes according to temperature variation; wheras the Fig. 4 shows the result calculated in CFD Solver.

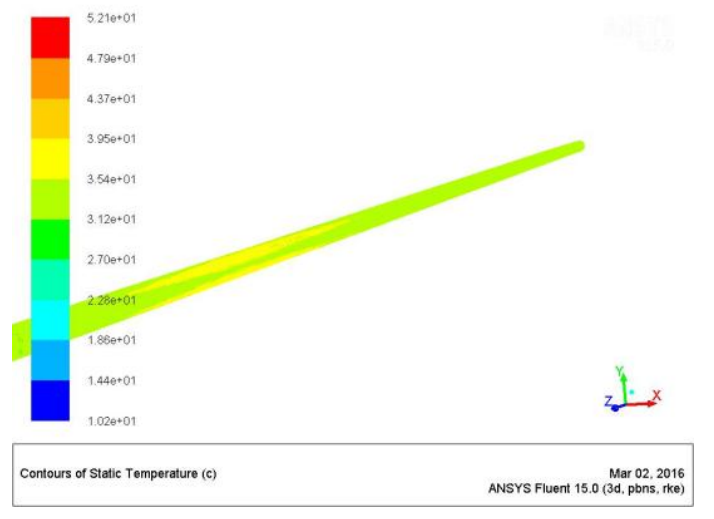

Fig. 3a Temperature variation in inner tube

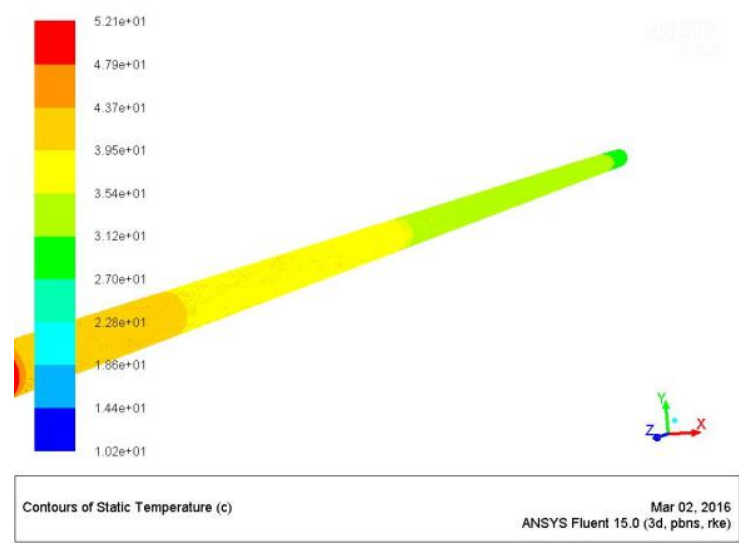

Fig. 3b Temperature variation in inner annulus

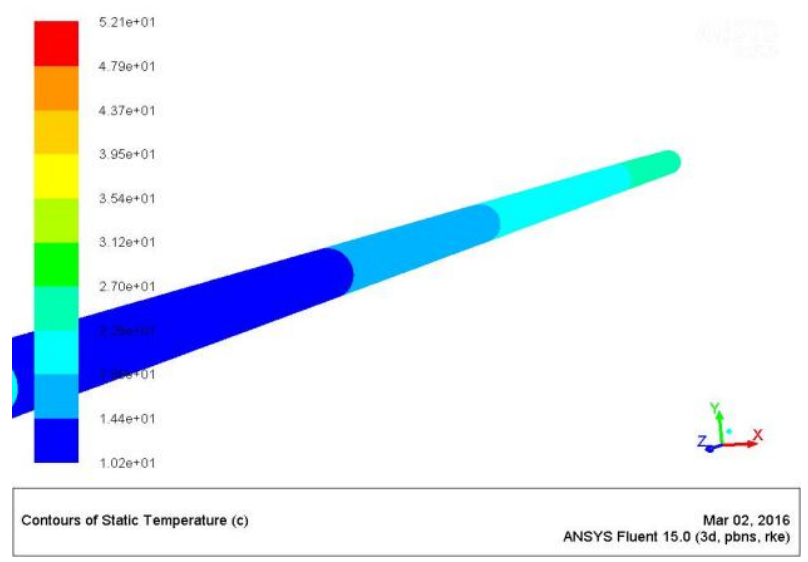

Fig. 3c Temperature variation in outer tube

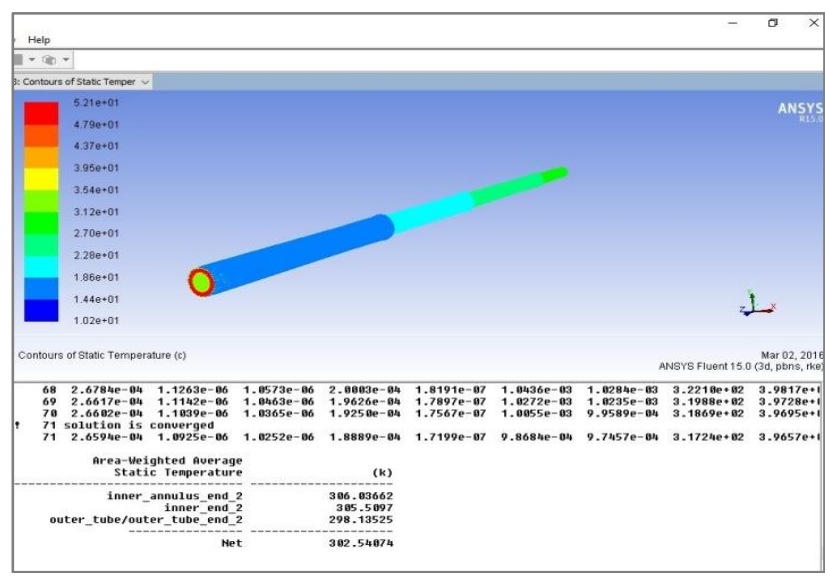

Fig. 4 Results shown in Solver

Table 1 Result Table for $\mathrm{V}_{\mathrm{n}}=\mathrm{V}_{\mathrm{h}}=\mathrm{V}_{\mathrm{c}}=35 \mathrm{l} / \mathrm{min}$

\begin{tabular}{|c|c|c|c|}
\hline Fluid & Input & (Exptl)Output & (CFD)Output \\
\hline Cold & $10.23^{\circ} \mathrm{C}$ & $21.98^{\circ} \mathrm{C}$ & $24.98^{\circ} \mathrm{C}$ \\
\hline Hot & $52.11^{\circ} \mathrm{C}$ & $30.75^{\circ} \mathrm{C}$ & $32.88^{\circ} \mathrm{C}$ \\
\hline Normal & $28.23^{\circ} \mathrm{C}$ & $34.89^{\circ} \mathrm{C}$ & $32.5^{\circ} \mathrm{C}$ \\
\hline
\end{tabular}

Table 2 Result Table for $V_{h}=201 / m i n ; V_{n}=V_{c}=35 l / m i n$

\begin{tabular}{|c|c|c|c|}
\hline Fluid & Input & (Exptl)Output & (CFD)Output \\
\hline Cold & $10.27^{\circ} \mathrm{C}$ & $18.56^{\circ} \mathrm{C}$ & $20.20^{\circ} \mathrm{C}$ \\
\hline Hot & $51.07^{\circ} \mathrm{C}$ & $39.44^{\circ} \mathrm{C}$ & $40.05^{\circ} \mathrm{C}$ \\
\hline Normal & $28.30^{\circ} \mathrm{C}$ & $31.18^{\circ} \mathrm{C}$ & $30.90^{\circ} \mathrm{C}$ \\
\hline
\end{tabular}




\section{Conclusions}

Following conclusions can be drawn from our present study.

1) Study of the experimentation was complete and the procedure of experimentation was briefed here.

2) Experimentation was carried out for both flow arrangements, but here we mainly focused on two conditions, $\mathrm{V}_{\mathrm{n}}=\mathrm{V}_{\mathrm{h}}=\mathrm{V}_{\mathrm{c}}=35 \mathrm{l} / \mathrm{min}$ and $\mathrm{V}_{\mathrm{h}}=20 \mathrm{l} / \mathrm{min}$; $\mathrm{V}_{\mathrm{n}}=\mathrm{V}_{\mathrm{c}}=35 \mathrm{l} / \mathrm{min}$.

3) The flow analysed was co current parallel flow with $\mathrm{N}-\mathrm{H}-\mathrm{C}$ arrangement (Normal water in the innermost tube, Hot in the intermediate and Cold at the outermost tube)

4) When the flow rate is decreased in the hot tube there is decrease in the temperature rise of the normal and cold fluids

5) Results are presented in graphical as well as tabular form

6) Tolerating small difference, CFD results are close to the experimental results.

\section{References}

G.A. Quadir,N. J. Salman Ahmed, Irfan Anjum Badruddin, (2014), Experimental investigation of the performance of a triple concentric pipe heat exchanger, International Journal of Heat and Mass Transfer, 62, 2014, 562-566.

G.A. Quadir, Saqab S. Jarallah, N. J. Salman Ahmed, Irfan Anjum Badruddin,(2014), Numerical investigation of the performance of a triple concentric pipe heat exchanger, International Journal of Heat and Mass Transfer, 75, 165172.

Patel Dharmik A., V. D. Dhiman, Jignesh J. Patel, Ravi Engineer, (2015), CFD analysis of triple concentric tube heat exchanger, University Journal of Research, 01, 30-44.

Tejas M. Ghiwala, Dr. V. K. Matawala, (2014), Sizing of triple concentric pipe heat exchanger, International Journal of Engineering Development and Research, 02, 1683-1692.

Vishwa Mohan Behera, D.H. Das, Ayushman Nayak, (2014), Numerical analysis of triple tube heat exchanger using ansys, (2014)International Journal of Scientific \& Engineering Research, 05, 1226-1231.

S. Kakac, H. Liu (1998), Heat Exchangers, Selection, Rating, and Thermal Design, CRC Press, New York, pp. 283-328.

Richard H. Pletcher, John C. Tannehill, Dale A. Anderson, (2013), Computational Fluid Mechanics and Heat Transfer, CRC Press, Third Edition. 